\title{
Foregrounding backstage activities for engaging children in a FabLab for STEM education
}

Katrien Dreessen and Selina Schepers

Social Spaces, LUCA School of Arts, KU Leuven

C-mine 5, 3600 Genk, Belgium

katrien.dreessen@luca-arts.be,selina.schepers@luca-arts.be

Corresponding author: Katrien Dreessen

\begin{abstract}
To tackle the worldwide shortage of graduates with a STEM diploma, governments are allocating funds to STEM education. This article focuses on the potential of FabLabs in relation to STEM education for non-expert users; more specifically, children of $6-16$ years old. We describe two case studies - 'Wa Make?' and 'Making Things!' - that are part of a long-term process of engaging local non-expert users in FabLab Genk. Although the goal of the two cases was the same (i.e. getting children acquainted with a FabLab), their setups differed completely. By comparing the two cases, we address the importance of backstage activities for engaging nonexpert users in STEM-related activities in FabLabs and report on the different front- and backstage activities that we undertook in both case studies. We discuss how focusing on these backstage activities resulted in us moving away from the ' 30 -minute workshop model' to engage non-expert users in FabLab Genk in the long-term. We also report on how it urged us to thoroughly reflect upon the roles that adults (i.e. the researchers, youth workers, teachers, etc.) take on in STEM-related activities in FabLab. With our article we aim to provide handlebars for engaging children in a FabLab for STEM educational purposes, through foregrounding backstage activities. By doing so, this paper advocates to consider FabLabs as more than merely technical infrastructures and to foreground the importance of backstage activities in processes to engage non-expert users in STEM education.
\end{abstract}

\section{Author Keywords}

FabLab; non-expert users; STEM; children; backstage; frontstage. 


\section{INTRODUCTION}

In the past 25 years, STEM ('Science, Technology, Engineering, Mathematics') education has received increasing attention worldwide. The aim of promoting STEM education is two-fold: on the one hand, promoting scientific literacy of young people and on the other, attracting young people in secondary and higher education to pursue scientific and technical professions and/or research careers. Moreover, STEM education for girls and young people with vulnerable social economics backgrounds receives special attention, as these groups remain underrepresented [1]. Hence, this policy tries to tackle the worldwide shortage of graduates with a STEM diploma. As part of this policy, Blikstein \& Worsley [2, p. 67] report on the recent increase in educational, after school programs focusing on STEM: “activities centered on robotics, physical computing, science, or math proliferated in recent years due to the availability of low-cost equipment (Arduino-like platforms), and the popular perception that these noncurricular STEM skills were becoming crucial for the job market".

Next to its integration in (after) school programs, STEM education has resorted more and more to digital fabrication spaces. Although these spaces take on different forms (Hackerspaces, Makerspaces, FabLabs, etc.), they can all be considered as community spaces that offer public, shared access to high-end manufacturing equipment [3]. Specifically, FabLabs are open workplaces (currently 1251 worldwide), aimed to explore the implications and applications of personal fabrication $[4,5,6,7]$. The contribution of our research lies in the exploration of the potential of FabLabs in relation to STEM education for non-expert users; more concretely, children of 6 - 16 years old. Reflecting on two strategies of involving children in FabLab Genk, we describe two case studies (see: ' 3 ' and '4') and report on the front- and backstage activities that we undertook in both case studies (see ' 5 '). We discuss how focusing on the backstage regions resulted in us moving away from the '30-minute workshop model' and urging us to reflect upon the roles that adults play in STEM-related activities for children in FabLabs (see '6'). Finally, we formulate the limitations of our study (see '6.3'). With our article we aim to provide handlebars for engaging children in a FabLab for STEM educational purposes, through foregrounding backstage activities. We now go deeper into STEM education finding its way to FabLabs, the challenges it poses and the relevance of backstage activities (see ' 2 '). 


\section{BACKGROUND}

Clarifying why STEM education is resorting more and more to digital fabrication spaces, research [8] has shown that workshops aiming to enthuse children for STEM better start from the spare time context than from a school-related context since schools prioritize too much abstract thinking and often leave little to no room for play and fun [9]. After all, STEM activities organised outside of the school context, tend to be more tactile and situated in or connected to everyday settings. "Project ideas and themes should be connected to students' lives, interests, passions, and their communities", as stated by Blikstein \& Worsley [2, p. 74]. STEM activities organised during out-of-school-time thus provide children with important opportunities to spark, sustain and deepen their interest in STEM. These activities are also more likely to develop and expand their understanding of STEM and advance to pursuing careers in STEM-related fields $[10,11]$. Moreover, because most out-of-school environments are low-stakes (non-evaluative) environments, they provide opportunities for students to play or experiment with science and pursue new ideas or particularly motivating ones when there is interest. This in contrast to curricular activities, where there is often more pressure to follow particular procedures or arrive at specific answers $[2,8]$.

STEM education finding its way to FabLabs does pose some challenges, such as 'epistemological dilution'. This phrase, coined by Papert in 1999 [12] describes the gradual degradation in the level of instruction and usage of Lego in classrooms. More recently, Blikstein [13] described in this respect the "keychain syndrome" to point out the focus on the look of the product (making a customized keychain as a first exercise in laser-cutting) instead of focusing on learning to use the machine. Furthermore, as stated by Taylor et al [14], digital fabrication spaces can operate as meeting places that adapt and outreach their activities and facilities to the needs and interests of, for instance, (local) communities. Although the group of people using the available infrastructure is growing considerably, many non-expert users are often impeded to engage in FabLabs and other digital fabrication spaces. Not only the lack of skills and experience to design for and use the technical infrastructure (hardware and software) is an important barrier for these users, but also the enormous variety of different technologies and tools in these spaces 
makes it difficult for them to experiment with $[15,16]$. For example, each 3D printer has its own properties, uses a specific technology and type of material influencing the size, strength and finishing of the printed object [8, 17, 18]. Furthermore, since most digital fabrication and software design tools are designed for expert users, non-expert users need to invest time and energy to learn how to use them $[17,19,20]$. This means that even though the ideal of Fablabs is sharing tools, knowledge and skills, these spaces often fail to engage a diverse public of people with no technical background [21, 22].

However, in terms of STEM education it is crucial to involve non-expert users in a FabLab in a considerate, thoughtful way; particularly when it comes to children or teenagers. Blikstein \& Worsley [2] have described how young novices coming into a FabLab need a considerable amount of facilitation and introduction to the FabLab and its infrastructure. When this was absent, some users felt lost, frustrated and disempowered; they reported an even lower selfesteem than before coming to the FabLab. Moreover, Taylor, Clarke \& Gorkovenko [23] point out that it is necessary to think not just about how non-expert users might access equipment, but also about the knowledge and relationships that will enable them to come together and engage in STEM-related activities. Dreessen \& Schepers [18] foreground the importance of the roles adults take on when working with children in a FabLab. To motivate children in STEM-related activities, it is - for instance - important to take on a role as motivator, to provide praise or encouragement to the child participants, remove distracting resources or adapt the activities on the fly to keep the participants engaged. When organising STEM education for non-expert users in FabLabs, it is therefore essential to reflect upon how to approach these activities.

\subsection{BACK- AND FRONTSTAGE ACTIVITIES}

To contribute to ongoing research, this article addresses the importance of backstage activities for engaging non-expert users through STEM-related activities in FabLabs; with a specific focus on children and teenagers. Research on children's involvement in FabLabs is mostly focussed on education, for instance on how making is integrated in different learning spaces (e.g. schools, libraries, museums), how educational toolkits can engage children in making and how making is embedded in a school's curriculum $[24,25,26,27,28]$. However, the majority of literature that 
is dedicated to children's involvement in FabLabs focuses on the frontstage activities. We refer to Goffman's [29] distinction between 'backstage' and 'frontstage' regions in which everydaylife interaction takes place. Within this dramaturgical perspective, frontstage activities take places before an audience, whereas in the backstage region we rehearse or prepare ourselves for upcoming frontstage performances. When translated to STEM education in FabLabs, frontstage activities can be considered to be the driving forces and include workshops, classes, meetings, making sessions, etc., wherein makers, teachers, FabLab managers, designers, researchers, participants, stakeholders, etc. come together to work around a specific topic or object of design [30]. While these frontstage activities are necessary and important, less documented is how makers, teachers, FabLab managers, designers, researchers, participants, stakeholders, etc. engage in backstage activities that are fundamental for the organisation and success of these above-mentioned frontstage activities [11]. According to Dindler \& Iversen [31] the backstage work is evenly important as the frontstage activities; this is also the case when it comes to STEM education in FabLabs. Backstage activities are the "fuzzy and chaotic processes" that emerge before, between and after the frontstage activities and tie them together [30, p. 5]. Specific examples of these backstage activities might entail informal gatherings, phone calls, coffee breaks or Facebook conversations. In relation to the FabLab initiatives described in this paper, these backstage initiatives included an e-mail campaign to elementary schools, coffee breaks during workshops with teachers and WhatsApp messages with youth workers to prepare certain aspects of the workshops (for an overview of the front- and backstage activities that took place during the two case studies central to this paper, see: 'Table 1. Overview of the two case studies').

\section{CASE STUDIES: 'WA MAKE?' AND 'MAKING THINGS!'}

To get a clear view on the importance of backstage activities for engaging non-expert users in STEM-related activities in FabLabs, we now describe two case studies that are part of a longterm process of engaging local non-expert users in FabLab Genk. FabLab Genk was set up in 2011 as part of a European project (INTERREG IV). In the early days of FabLab Genk, the focus was - like most FabLabs - mainly on the technical infrastructure offering visitors (primarily students of local art and design schools) access to the machinery, tools and skills. 
Over the years, this strategy raised questions regarding (economical) sustainability and how to open up the Lab towards participation of a broader audience (including non-expert users). Hence, Fablab Genk aimed to be more than just a physical infrastructure offering access to machines; an issue numerous FabLabs struggle with [32]. An ongoing process was set up in FabLab Genk, initiating various activities (workshops, exhibitions, demonstrations, etc.) to actively involve non-experts. In this way, the emphasis on the FabLab as a technical infrastructure was extended towards a community space that offers public, shared access to high-end manufacturing equipment. The FabLab slowly became a flexible infrastructure that collaborates with and supports local actors in their (making) activities and changes in function of the communities' needs and wishes. In doing so, FabLab Genk attempts to nurture long-term participation from other and new groups than the traditional makers. In this way, the FabLab tries to overcome a well-known shortcoming of the traditional FabLab concept which originated from a rather technocratic viewpoint, focussing on the machines. And although the idea of knowledge sharing (via fabmoments) in a global network has always been part of the concept, little attention was giving on aspects of community building or setting up sustainable relationships with local actors [33].

In this context, two case studies were set up - being 'Wa Make?' ('3.1') and 'Making Things!' ('3.2') - to engage with non-expert children in FabLabs. Both of these case studies were carried out by two researchers (i.e. the authors of this paper), who were occasionally joined by four other FabLab team members (e.g. FabLab manager).

\subsection{CASE DESCRIPTION 'WA MAKE?'}

The first case -'Wa Make?' (local slang for 'how are you?') - is a project funded by Flanders Make, the Flemish strategic research centre for the manufacturing industry. Carried out by FabLab Genk, 'Wa Make?' aimed to introduce school children (10 - 14 years old) to digital fabrication technologies and enthuse them for STEM. The objective of Flanders Make was to fund local FabLabs (six in Flanders) to organise workshops for local schools to reach as many children as possible. Each school could choose the activities to be organised in the different FabLabs spread out over Flanders; ranging from laser cutting keychains to building rockets or 
tinkering with electronics. For the 'Wa Make?' workshops, we chose to provide the children with a rather open workshop and tried to include elements that the children and teachers could finish at school or at home. Over a period of six months (October 2016 - March 2017), 28 half-day workshops were organised, involving 415 children, 30 teachers, and six moderators from FabLab Genk. The children all visited the FabLab with their class. Selection of the participants was based on registration for the workshop that was communicated via a mail campaign that was sent on several occasions to local schools. The date of the workshop was decided in consultation with the school.

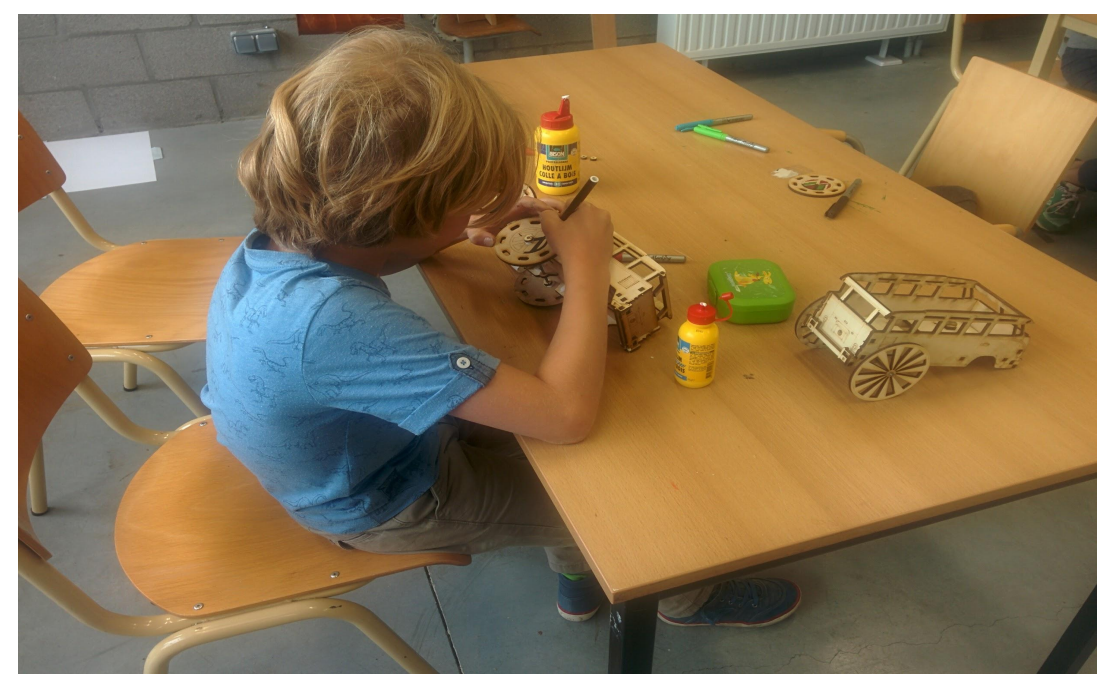

Figure 1: impressions of a 'Wa Make?' workshop

Schools could choose between 3 half-day workshops: building a zoetrope (i.e. a system to make an animated movie, consisting of an upright cylinder with vertical openings), building an airplane or moving car (see: Figure 1), or creating a musical instrument. Although the subject of the workshops was fixed, we also communicated to the schools that we could change the content of the workshop based on their (curricular) requests, but no schools took us up on this offer. Each workshop started with an introduction to FabLab Genk by the involved researchers. The children and teacher(s) were taken on a tour through the Lab and were introduced - by small demonstrations - to the available machinery (laser cutter, 3D printers, CNC mill, etc.). Next, most of the workshops entailed experimenting with LittleBits - electronic building blocks that can be connected through magnets, developed for easy prototyping (see: Fig. 2) - and using the infrastructure of the FabLab. At the end of each workshop, the children - and involved teachers - 
were asked to evaluate the workshop, through an open questionnaire and short unstructured interviews with the children conducted by the researchers.

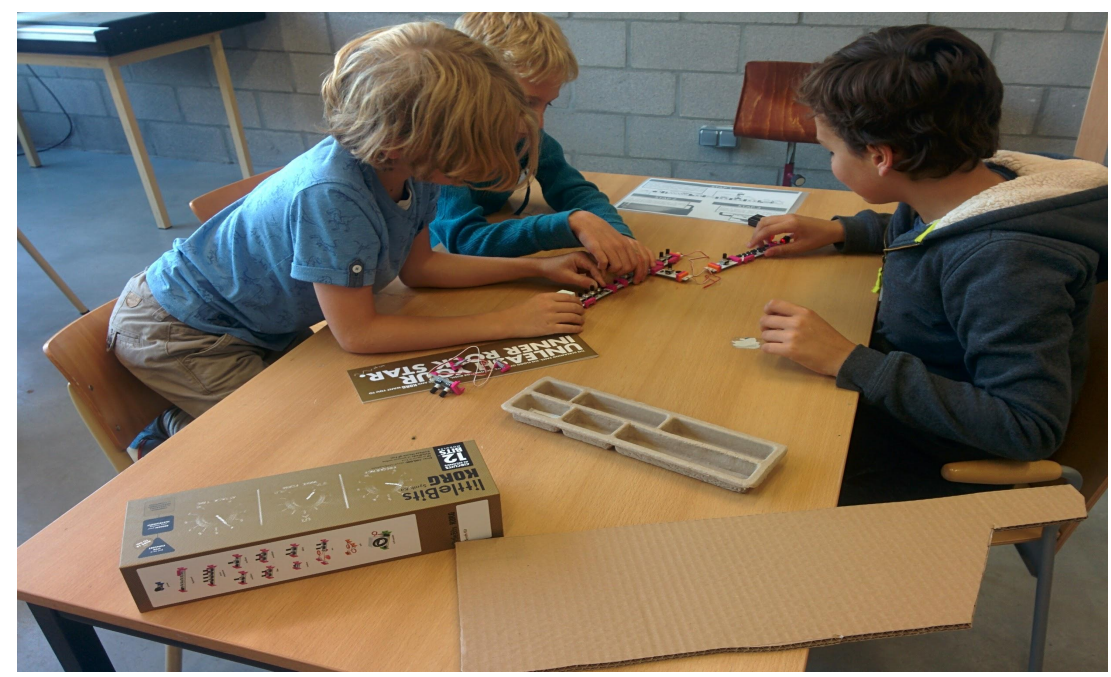

Figure 2: using LittleBits to make a keytar

\subsection{CASE DESCRIPTION 'MAKING THINGS!'}

The second case is 'Making Things!', a long-term Participatory Design process (2015 - ongoing) to design workshops together with children of $6-16$ years old, funded by LUCA, School of Arts (www.luca-arts.be). This process entails a collaboration between FabLab Genk and a local branch of youth work organisation 'LYWO' (pseudonym; partnering youth work organisation). 'LYWO' aims to offer activities in leisure time with extra attention for the well-being of the (mostly socially disadvantaged) children. An important value of the organisation is that the children should have a say in choosing which activities are organised. 'Making Things!' answers to the specific need of 'LYWO' to offer accessible STEM workshops to children. The process of 'Making Things!' can be considered as a capacity building process, in which FabLab Genk provides the children and youth workers with the necessary skills, confidence and material (in the form of adaptable templates) that they can continue to use after completion of 'Making Things!' (and thus without the involvement of the researchers) [6]. In 'Making Things!', 65 local children and eight youth workers of LYWO participated. The youth workers all fulfilled different roles (i.e. facilitator, motivator, caregiver, proxy, co-designer, playmate and friend) during the - frontstage and backstage activities of the - process. We particularly collaborated 
intensely with 'Abby' (pseudonym; one of the involved youth workers who was most involved in the 'Making Things!' case study). For a thorough review on the roles Abby - and other youth workers - played in the process, we refer to [18]. Selection of the participants was based on the activities of the youth work organisation. As participation of the children in the LYWO activities is voluntary and (weekly) presence is not mandatory, the group of children changes every week. However, a core group of about 25 participants attends the activities on a weekly base.

The activities we engaged in with the participants consisted of (1) participatory observations and sensitising packages; (2) a first iteration of the workshops; (3) evaluations; and (4) a second iteration of the workshops, followed by evaluative interviews. First, six sessions of participant observations [34] - of more than 60 boys and girls - were carried out in the period between April and May 2016, to gain insights in the children's lifeworlds and generate ideas for the design of the workshops. Inspired by Van Mechelen et al [35], 20 children also received a sensitising package: two assignments in which the children - through drawing and crafting - expressed their ideas on the workshops. In the second project phase, 33 of these children participated in a lowtech workshop on 29 June 2016. They created and customized paper ornaments, jumping-jack puppets and necklaces. In the period of July - November 2016, a series of three more low-tech FabLab workshops took place in which approximately 30 children participated. They experimented with some of the available machines to assemble and customize laser cut boxes. This allowed them to familiarize with the FabLab's infrastructure and provided us with insights in the making skills of the children. Third, informal brainstorms were carried out (June December 2016). The researchers, youth workers and children brainstormed about their experiences and expectations of the past and future workshops. We also carried out semistructured interviews with three youth workers. The last phase consisted of four high-tech workshops (April - November 2017) in which approximately 50 children experimented with electronics, hardware and software via Ozobot, Makey Makey and soldering. For the teenagers that participate in the 'LYWO' activities, we organised - on their request and after some demonstrations in and introductions to the FabLab - a workshop in which they created, customised and designed jewellery during this phase. Afterwards, the workshops were evaluated via semi-structured interviews with the children and youth workers (cf. infra). 


\section{METHODOLOGY}

As a methodological framework for the two case studies that are central to this paper, we refer to case study research. Yin defines a case study as "an empirical inquiry that investigates a contemporary phenomenon within its real-life context, especially when the boundaries between phenomenon and context are not clearly evident" [36, p. 13]. The case study, like other research strategies, is a means to research an empirical topic by following a set of prespecified procedures. Over several years of ethnographic fieldwork, our field documentation of both case studies included audio- and video recordings, sensitising packages, transcribed interviews and logged field notes. During the 'Wa Make?' workshops, we also distributed a one-page questionnaire, containing a few yes/no, multiple-choice and open-ended questions (as requested and composed by Flanders Make) which were complemented with open group interviews with the children and their teacher(s). The questionnaires as well as the group interviews asked how the children and teachers experienced the workshops, if they would like to be part of follow-up activities, if they could compare it with things they are doing at school, etc. Furthermore, approximately one week after taking part in the workshop, the teacher(s) provided us with additional insights concerning the children's experiences in the workshop that were discussed during informal conversations or structured class discussions. To evaluate and compare both case studies, similar questions were posed in the questionnaires and interviews for the "Making Things!' case study. For instance, the children that took part in the case studies were asked what the goal of the workshops was and with what other activities they would compare it. Furthermore, also the personal communication (mainly emails and chat messages) with the supervisors (i.e. teachers and youth workers) leading up to and in the aftermath of the workshop(s) was incorporated in the field documentation and analysed.

\begin{tabular}{|l|l|l|}
\hline \multicolumn{2}{|c|}{ OVERVIEW OF THE TWO CASE STUDIES: GENERAL } \\
\hline & 'Wa Make?' & 'Making Things!' \\
\hline total of children & 415 & 65 \\
\hline
\end{tabular}




\begin{tabular}{|c|c|c|}
\hline period & half a day & 2 years \\
\hline evaluation methods & $\begin{array}{l}\text { questionnaire, group } \\
\text { interviews with } \\
\text { children and } \\
\text { teachers }\end{array}$ & $\begin{array}{l}\text { observations, sensitizing packages, } \\
\text { group interviews with children, in- } \\
\text { depth interviews with youth workers }\end{array}$ \\
\hline context & school & leisure time \\
\hline $\begin{array}{l}\text { guidance besides } \\
\text { researchers }\end{array}$ & $\begin{array}{l}\text { teacher(s), funding } \\
\text { organisation }\end{array}$ & youth worker(s), specifically 'Abby' \\
\hline \multicolumn{3}{|c|}{$\begin{array}{l}\text { OVERVIEW OF THE TWO CASE STUDIES: FRONT- AND BACKSTAGE } \\
\text { ACTIVITIES }\end{array}$} \\
\hline frontstage activities & FabLab workshops & $\begin{array}{l}\text { series of activities: low-and high- } \\
\text { tech workshops, brainstorms }\end{array}$ \\
\hline $\begin{array}{l}\text { backstage activities } \\
\text { - before the project }\end{array}$ & $\begin{array}{l}\text { mail campaign to } \\
\text { schools, e-mail and } \\
\text { phone } \\
\text { correspondence } \\
\text { (with principals and } \\
\text { teachers), } \\
\text { preparative } \\
\text { meetings with } \\
\text { funding organisation }\end{array}$ & $\begin{array}{l}\text { e-mail correspondence (with youth } \\
\text { workers), preparative meetings with } \\
\text { the youth work organisation, text or } \\
\text { chat messages (Whatsapp, Facebook, } \\
\text {...) with Abby and other youth } \\
\text { workers, phone calls with Abby, } \\
\text { informal gatherings with Abby (and } \\
\text { other youth workers) }\end{array}$ \\
\hline - during the project & $\begin{array}{l}\text { coffee breaks during } \\
\text { workshops with } \\
\text { teachers }\end{array}$ & $\begin{array}{l}\text { coffee breaks during workshops with } \\
\text { youth workers, attending activities } \\
\text { not related to the case study (e.g. } \\
\text { charity cookie sale) }\end{array}$ \\
\hline
\end{tabular}




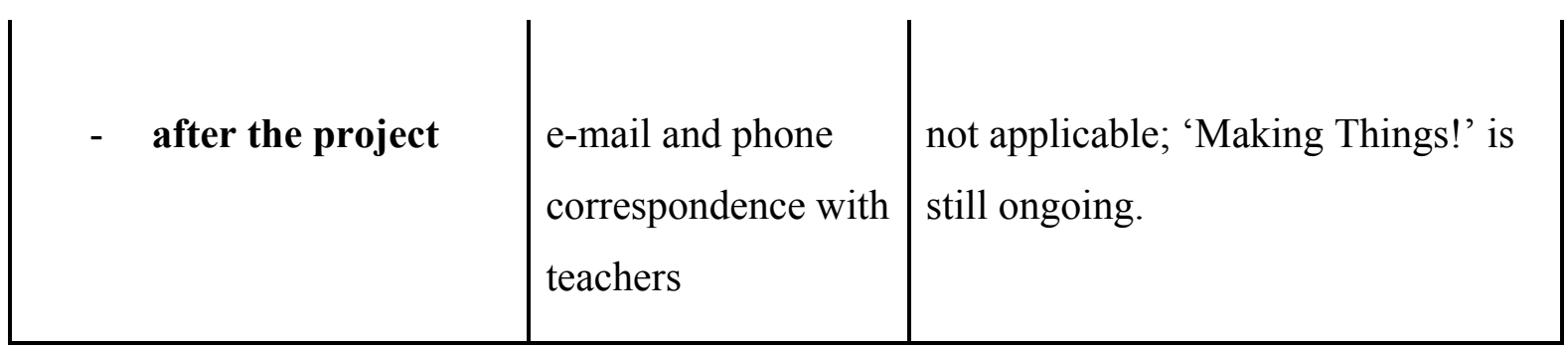

Table 1. Overview of the two case studies

The two main participating researchers independently conducted qualitative analyses of the process documentation of each case separately. Various coding iterations were performed on the primary data (i.e. 415 questionnaires, 42 group interviews with children, 6 observations, 3 indepth interviews with youth workers, 23 email conversations and 17 chat messages), starting with an open coding to generate an initial set of codes describing the empirical data. These two iterations of coding were done separately by the authors of this article. The final coding iteration, in which the codes were clustered and grouped into categories, was a joint effort.

For this paper, most interesting was a small group of children ( 3 girls and 2 boys) that took part in both trajectories; during two 'Wa Make?' workshops the researchers recognized the children from the 'Making Things!' trajectory. In one of the following 'Making Things!' workshops, we interviewed them separately about the two different trajectories they participated in. To present the results, pseudonyms are used in this paper to preserve the privacy of each participant. Citations are translated from the original language to English.

\section{FINDINGS}

To lower the threshold for non-expert users to engage with FabLab Genk for STEM-related purposes, the analysis of the case studies indicates the importance of backstage activities. We now report on these activities in both of the cases.

\subsection{BACK- AND FRONTSTAGE ACTIVITIES IN 'MAKING THINGS!'}

In 'Making Things!', it is clear that the frontstage activities entailed the activities organized in FabLab Genk, being the observations, brainstorms and low-and high-tech workshops. These 
frontstage activities were embedded in a long-term trajectory of backstage activities, including informal meetings (over coffee) with the youth workers, Whatsapp and Facebook messages as well as phone calls with the youth workers, coffee breaks during workshops with youth workers and participation in activities organised by 'LYWO' (e.g. their monthly jam sessions and charity cookie sale). The case study analysis of 'Making Things!' shows that engaging in backstage activities (more specifically the activities organised by 'LYWO' that had no direct link with the 'Making Things!' process or the FabLab) was essential in gaining trust from the children and youth workers. For instance, by taking part in a dropping game - organised by LYWO; this was not part of the 'Making Things!' activities - and putting ourselves on the level of the children while playing, resulted in us being seen as a playmate. This also built trust among the children, towards Abby and subsequently also towards the activities of 'Making Things!'.

Engaging in backstage activities was also important in getting to know the children and their interests in a more informal way, complementing the insights gained from the frontstage activities in meaningful ways. An important value of 'LYWO' is that children have a say in choosing which activities are to be organised. Therefore, in 'Making Things!', we attempted to achieve this by letting the actual workshops and making sessions be preceded by a trajectory of participant observations, sensitizing packages but also other informal contact moments that were situated on the backstage region. Through doing this, we were able to design them in a way that better suits the needs and wishes of the participants. A striking example of this entailed the activities that we organised for the teenagers in the last phase of the project. In the FabLab, we provided approximately 15 teenaged girls with different sorts of elements (plastic shapes, wooden letters, metal rings to hold the different elements together, etc.) with which they could make necklaces, bracelets and earrings. We also asked them to design their own jewellery by drawing; afterwards, we actually fabricated the ideas that the girls had drawn by laser cutting them. These workshops were aligned with the personal interests and lifeworlds of the girls, as the idea of organising a jewellery workshop in FabLab Genk came from them. The girls expressed their ideas for a jewellery workshop through informal chats - along the coffee machine in the FabLab - with Abby and the researchers. 
Although these backstage activities required a lot of time, effort and energy, they allowed the researchers to build meaningful relationships with the children and youth workers involved, in between or even before the workshops. For instance, as we worked with 'Abby' over an extended amount of time, our interactions with her became more informal. This was illustrated by us having less formal conversations, becoming friends on Facebook and sending private messages via Whatsapp. In this sense, Abby's involvement in the frontstages activities of the 'Making Things!' process formed the basis of a friendship existing in the backstage activities as well [18]. Building further on this relationship with Abby but also with the 'LWYO' children and other youth workers, 'Making Things!' can be seen as a symbiotic agreement between both parties (i.e. sustainable connections that are valuable for both parties [30, 31]). Both parties (the researchers and the youth workers of LYWO) departed from the same values: for FabLab Genk, it implies intensifying the relationship with the local children and 'LYWO' by engaging them in the FabLab; for the youth organisation it means creating specific STEM workshops for their target. These shared values appeared to fit harmoniously, which contributed to the successful formation of a symbiotic agreement in the process of 'Making Things!'

\subsection{BACK- AND FRONTSTAGE ACTIVITIES IN 'WA MAKE?'}

Although the intention of the 'Wa Make?' workshops was to take first steps in building relationships with local actors, the analysis showed that the focus was almost entirely on the frontstage activities (i.e. the 28 half-day FabLab workshops). The backstage activities were limited to a mail campaign to schools (set up by the researchers), e-mail correspondence (between the researchers, four other FabLab team members and interested teachers or principals) and preparative meetings with the funding organisation. Thus, mainly involved in the backstage activities of 'Wa Make?' - next to the involved researchers - were the involved teachers as well as employees of Flanders Make, who funded the workshops. It is important to note that the participating children were only involved in the frontstage activities. Although new relationships were formed through participating in the workshops (e.g. with the involved teachers or children), they did not appear to be sufficient for enabling long-term participation in the FabLab. We repeatedly questioned the relevance of these short half-a-day workshops and also suggested moving the STEM-activities away from the school context during the preparative meetings; 
however, the funding organisation's main objective left no room for this. Despite several efforts of setting up a long-term trajectory with the schools who participated in the 'Wa Make?' workshops, the outcome of these backstage activities was very limited. The contacted teachers and principals were all excited but ultimately different thresholds blocked a potential collaboration. The most important obstacle for the schools was fitting this collaboration in the curriculum of the school; multiple teachers stated that there was little to no room left to integrate recurring extra-curricular activities in the study program. In this sense, we can state that no symbiotic agreement was formed between the involved stakeholders [30, 31]: there was no shared value or starting point. The workshop was considered as an opportunity that could be consumed by the school and not as a joint project that could be developed further on or integrated into the school's curriculum. This was manifested by the teachers playing a waiting game and not taking up a role during the workshops.

\section{DISCUSSION}

Foregrounding backstage activities in the case studies of 'Wa Make?' and 'Making Things!'

allowed us to reflect on our ways of engaging children in STEM-related purposes in a FabLab context. We now discuss how this resulted in us moving away from the '30-minute workshop model' to engage non-expert users in FabLab Genk in the long-term ('6.1'). We also report on how it urged us to thoroughly reflect upon the roles that adults (i.e. the researchers, youth workers, teachers, etc.) take on in STEM-related activities in FabLab Genk ('6.2'). Based on our case-analysis, we also formulate the limitations of the research ('6.3').

\subsection{MOVING AWAY FROM THE '30-MINUTE WORKSHOP MODEL’}

According to Blikstein [13], the move from STEM education into FabLabs has created an incentive for standardization and lead to the proliferation of the "30-minute" workshop model or the "keychain syndrome"; fast, scripted and introductory workshops in which children resort to making keychains and other trivial objects. This impedes them from moving on to more complex projects that require more complex facilitation and infrastructure $[2,13]$. Related to this is the concept of deep making by Bergner and Chen [36] that foregrounds a framework for the design 
of curricular modules that facilitate learning of transferable content-knowledge. Deep making entails more that just knowing a fabrication procedure (e.g., how to use a laser-cutters), but also understand why this procedure is carried out in a certain way through continuity of multiple experiences over several sessions of creating tangible and shareable artifacts.

The analysis of 'Wa Make?' showed that, in essence, the organized workshops can be described as "30-minute" workshops $[2,13]$. The children were engaged in the FabLab through relatively short and clearly defined activities. Although they experimented with the LittleBits electronics and did partake in some introductory activities with the FabLab's machinery, they never really engaged in more complex or iterative projects. The reason for this setup was the clear objective of Flanders Make to provide the children with a short-term, STEM-related introduction to several FabLabs in Flanders. These "30-minute" workshops are excellent as a first contact with digital fabrication and STEM in general [2, 13]; and, answering to the requests of the funding organisation, the 'Wa Make?' workshops did just that. However, this also resulted in the absence of backstage activities for the trajectory: since we were unable to form meaningful relationships with the (teachers of) local schools and set up joined projects, we resorted to these short, scripted workshops. Answering directly to the needs of the funding organization, putting time and effort in engaging in backstage activities simply was unnecessary and even unsupported by Flanders Make. Nevertheless, Blikstein \& Worsley [2] indicate that a real making project takes several cycles of iterations, which are hard to fit into a one-size-fits-all format. Although FabLabs nurture a safe and productive space for long-term projects, these spaces often never get to this point.

In contrast, we believe that with 'Making Things!', we achieved this goal. Through contextualizing the workshops in a long(er)-term trajectory, the children got beyond simple, introductory activities, and started experimenting. During the LittleBits workshops, for instance, the children first created the desired end result and afterwards began experimenting and tried out different compositions with the building blocks: "in the beginning ['Nora'] just wanted to make the right composition and afterwards, [she] started experimenting with the different components" ('Abby', youth worker). We noticed that, through this, the children were more open to learning (see: Fig. 3). For instance, during the soldering workshop, 'Ravza' (girl, 6 y/o) 
explained: "trying to do that [soldering] was really fun (...). I have never done it but after several times I know now that some things melt and others don't'. Inevitably, this also required a great effort in setting up, maintaining and engaging in backstage activities, as described above. However, we believe that, through 'Making Things!' and its specific focus on the backstage activities, the children were better able and more eager to learn about STEM in the FabLab.

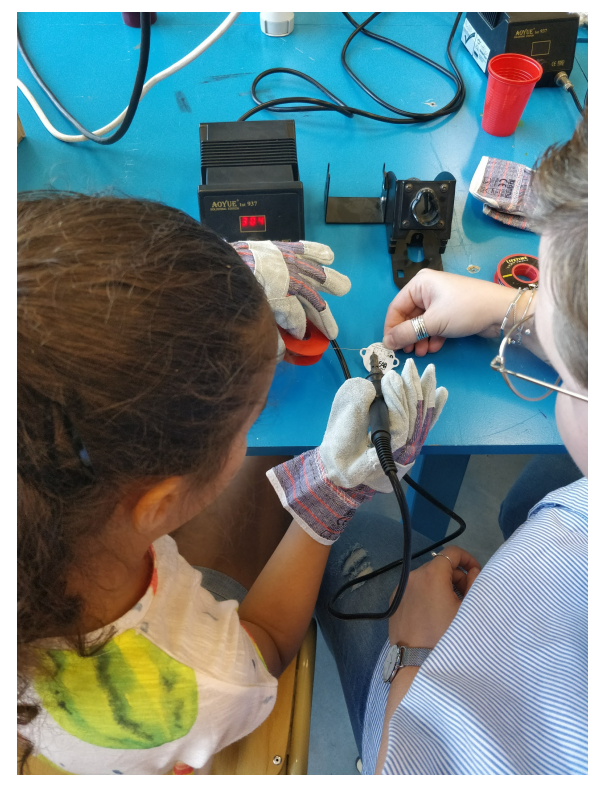

Figure 3: Experimenting with soldering

\subsection{THE ROLE OF TEACHERS VERSUS THE ROLE OF YOUTH WORKERS}

Finally, the analysis of the front- and backstage activities in the case studies made clear that the child participants engaging in FabLab Genk considered the adults involved in the process differently. While several models have been developed to discuss the roles of children and designers or design researchers in design processes, the roles of adult participants remain underexplored; there is not a specific, well-defined set of roles that is widely referred to in the literature $[37,38]$. In the literature that does exists on adult roles in design processes involving children, the role of the adult is typically discussed in terms of facilitating the children's role or collaborating with the child participants in the design process [39]. Both Molin-Juustila et al [40] and Benton and Johnson [37] have acknowledged the importance of other influential participants besides the children. The former [40] address the important role of the teacher in - among other 
things - ensuring that the design activities are appropriate and understandable for the children involved, while the latter [37] identify five roles that adults can play when doing design with children which special educational needs, being facilitators, motivators, care-givers, proxies, and co-designers and design partners. Dreessen and Schepers [18] complement these models with the roles of playmate and friend, while Barendregt et al [38] foreground the role of teaching staff when doing participatory design with children in special education.

In relation to this, in 'Wa Make?' - situated within the school context - the children saw not only the teachers but also the researchers and the four FabLab team members as authority figures. Among other things, this became clear from the children using formal language to address the adults and the teachers approaching the children as a typical adult: quite distantly yet warm, maintaining the role of a caretaker (e.g. taking children to the toilet) and not participating in the activities. In contrast, 'LYWO' youth worker Abby took part in all the STEM-related activities and put herself more on the level of the children while playing, which resulted in her being seen as a playmate or confidant. To elucidate this, we refer to Barendregt et al [33] who state that children and the adults around them often have a common understanding of the activities they usually perform and their roles in those activities. When a researcher enters the context and becomes a participant in those activities, a renegotiation of the activities and the participants' roles therein is needed. Often, misunderstandings about what the activity is and the roles of all participants in this activity will occur. For instance, "teachers present during a design workshop with children may think that their role is to guide the children towards a workable solution, while the designer is merely interested in the spectrum of ideas the children may have" [33, p. 2]. The analysis shows that because of the time and effort we put into backstage activities particularly for the 'Making Things!', these renegotiations with Abby came along more quickly, effectively and conflictless.

\subsection{LIMITATIONS OF THE STUDY}

It must be acknowledged that the described case studies are not beatific and are open to critique. For instance, since both 'Wa Make?' and 'Making Things!' target a specific group of participants (i.e. children and teenagers) it is not evident to formulate general concluding 
remarks that can be transferred to other non-expert users (such as adults). The findings should thus be interpreted in this light. And although the role of the teachers, youth workers and FabLab researchers is clearly of importance in engaging the children, this needs to be further investigated. Moreover, as the 'Making Things!' trajectory is still on-going (with activities planned until August 2019) it is not yet evident to draw definitive conclusions on whether or not the workshops were successful and achieved their goals; the described insights are thus preliminary findings.

\section{CONCLUSION}

In this article, we described how we engaged non-expert users - more specifically, children of 6 16 years old - in FabLab Genk. We reported on two specific case studies. On the one hand, 'Wa Make?' entailed a series of workshops organised within a school context, wherein limited effort was put into backstage activities when organizing the trajectory. On the other, by embedding STEM workshops in long(er)-term trajectories, departing from the children's interest and focusing on backstage activities - as was the case in 'Making Things!' - children get beyond "30 minutes', introductory activities. If this is the case, they start experimenting and are better able to open up to learning. Therefore, we advocate for thoroughly reflecting upon how to engage nonexpert users, such as children, in FabLabs for STEM educational purposes and putting time and effort in the backstage regions. We believe this allows for considering FabLabs as more than merely technical infrastructures.

\section{ACKNOWLEDGMENTS}

'Wa Make?' is funded by Flanders Make. 'Making Things!' is funded by LUCA School of Art's research platform. We thank the children, teachers and 'LYWO's youth workers for their participation.

\section{REFERENCES}


[1] Y. Beernaert, M. Kirsch, 2016. Beschrijving van kennis-netwerken STEM in Europa.

Kritische analyse van bestaande netwerken en aanbevelingen voor Vlaanderen. Report:

Departement Onderwijs en Vorming.

https://www.vlaanderen.be/nl/publicaties/detail/beschrijving-van-kennisnetwerken-stem-in-

europa (accessed 19 March 2018).

[2] P. Blikstein, M. Worsley, 2016. Children are not hackers. Makeology: Makerspaces as learning environments, 1(2014).

[3] K. Dreessen, S. Schepers, D. Leen, 2016. From Hacking Things to Making Things.

Rethinking making by supporting non-expert users in a FabLab. IxD\&A, 30, 47-64.

[4] S. Ananthanarayan, K. Siek, M. Eisenberg, 2016. A craft approach to health awareness in children. Proceedings of the 2016 Conference on Designing Interactive Systems (DIS '16). ACM [5] N. Gerschenfeld, 2005. FAB. The Coming Revolution on Your Desktop. From Personal Computers to Personal Fabrication. New York: Basic Books.

[6] B. Mikhak, C. Lyon, T. Gorton, N. Gershenfeld, C. McEnnis, J. Taylor, 2002. Fab Lab: an alternate model of ICT for development. Paper presented at the International Conference on Development by Design. Bangalore, India.

[7] C. Mota. 2011. The rise of personal fabrication. Proceedings of the 8th ACM conference on Creativity and cognition. ACM.

[8] B. Bevan, V. Michalchik, R. Bhanot, N. Rauch, J. Remold, R. Semper, P. Shields, 2010. Outof-school time STEM: Building experience, building bridges. Trends, Questions, and Findings from the Field June 2010. San Francisco: Exploratorium.

http://www.informalscience.org/sites/default/files/STEM_OST_Conf_Report.pdf (accessed 19 March 2018).

[9] S. L. Chu, R. Schlegel, F. Quek, A. Christy, K. Chen, 2017. 'I Make, Therefore I Am': The Effects of Curriculum-Aligned Making on Children's Self-Identity. Proceedings of the $2017 \mathrm{CHI}$ Conference on Human Factors in Computing Systems, 109-120, ACM.

[10] National Research Council, 2009. Learning science in informal environments: People, places, and pursuits. Washington, DC: The National Academy Press.

[11] J. A. Douglas, C. Katz, 2009. It's all happening at the zoo: Children's environmental learning after school. Afterschool matters, 8, 36-46. 
[12] M. Resnick, 2017. Thinking about Thinking about Seymour. Presentation presented at MIT Media Lab symposium. Cambridge, MA., January 26, 2017.

[13] P. Blikstein, 2013. Digital fabrication and 'making' in education: The democratization of invention. FabLabs: Of machines, makers and inventors, 4, 1-21.

[14] N. Taylor, U. Hurley, P. Connolly, 2016. Making community: the wider role of makerspaces in public life. Proceedings of the 2016 CHI Conference on Human Factors in Computing Systems. ACM.

[15] M. Hofmann, 2014. 3D printing gets a boost and opportunities with polymer materials. ACS Macro Letters, 3(4), 382-386.

[16] T. Ludwig, O. Stickel, A. Boden, V. Pipek, 2014. Towards sociable technologies: an empirical study on designing appropriation infrastructures for 3D printing. Proceedings of the 2014 conference on Designing interactive systems, 835-844, ACM.

[17] D. Ashbrook, S. Guo Shitao, A. Lambie, 2016. Towards Augmented Fabrication:

Combining Fabricated and Existing Objects. Proceedings of the 2016 CHI Conference Extended Abstracts on Human Factors in Computing Systems, ACM.

[18] K. Dreessen, S. Schepers, 2018. The roles of adult-participants in the backstage work of Participatory Design processes involving children. Proceedings of the 15th Participatory Design Conference, Hasselt and Genk, Belgium - August 20 - 24, 2018, Article No. 14.

[19] P. Carrington, S. Hosmer, T. Yeh, A. Hurst, S. K. Kane, 2015. "Like This, But Better": Supporting Novices' Design and Fabrication of 3D Models Using Existing Objects. iConference 2015 Proceedings.

[20] D. A. Mellis, 2014. Do-it-yourself fabrication of electronic devices. IEEE Pervasive Computing, 13.3, 22-29.

[21] S. Ananthanarayan, K. Siek, M. Eisenberg, 2016. A craft approach to health awareness in children. Proceedings of the 2016 Conference on Designing Interactive Systems (DIS '16), Brisbane, QLD, Australia - June 04 - 08, 2016, 724-735.

[22] A. Demeure, S. Caffiau, J. Coutaz, 2014. Activity based End-User-Development for Smart Homes: Relevance and Challenges. Intelligent Environments (Workshops), 141-152. [23] N. Taylor, L. Clarke, K. Gorkovenko, 2017. Community Inventor Days: Scaffolding Grassroots Innovation with Maker Events. Proceedings of the 2017 Conference on Designing Interactive Systems, Edinburgh, United Kingdom - June 10 - 14, 2017, 1201-1212. 
[24] M. Romero, B. Lille, 2017. Intergenerational Techno-Creative Activities in a Library Fablab. International Conference on Human Aspects of IT for the Aged Population, Springer. [25] K. S. Christensen, O. S. Iversen, 2017. Articulations on form properties and action-function couplings of maker technologies in children's education. Entertainment Computing, 18, 41-54. [26] M. Divitini, M. N. Giannakos, S. Mora, S. Papavlasopoulou, O. S. Iversen, 2017. Make2Learn with IoT: Engaging Children into Joyful Design and Making of Interactive Connected Objects. Proceedings of the 2017 Conference on Interaction Design and Children, 757-760, ACM.

[27] S. L. Chu, R. Schlegel, F. Quek, A. Christy, K. Chen, 2017. 'I Make, Therefore I Am': The Effects of Curriculum-Aligned Making on Children's Self-Identity. Proceedings of the $2017 \mathrm{CHI}$ Conference on Human Factors in Computing Systems, 109-120, ACM.

[28] N. Iivari, M. Kinnula, T. Molin-Juustila, L. Kuure, 2017. Multiple Voices in the Maker Movement-a Nexus Analytic Literature Review on Children, Education and Making. Proceedings of the 25th European Conference on Information Systems (ECIS), 1919-1933. [29] E. Goffman, 2002. The presentation of self in everyday life. 1959. Garden City, NY. [30] S. Bødker, C. Dindler, O. S. Iversen, 2017. Tying Knots: Participatory Infrastructuring at Work. Computer Supported Cooperative Work (CSCW), 26 (April 2017), 245-273 [31] C. Dindler, O. S. Iversen, 2014. Relational expertise in participatory design. In Proceedings of the 13th Participatory Design Conference: Research Papers-Volume 1. ACM. 41-50. [32] P. Troxler, 2010. Commons-based peer-production of physical goods: Is there room for a hybrid innovation ecology? Paper presented at the 3rd free culture research conference, Berlin, Germany.

[33] T. Zijlstra, 2013. The Failings of FabLabs. http://www.zylstra.org/blog/2013/09/thefailings-of-fablabs/ (accessed 26 October 2018).

[34] K. Musante, B. R. DeWalt, 2010. Participant observation: A guide for fieldworkers. Second Edition. Maryland, USA: Rowman Altamira, 2010.

[35] M. Van Mechelen, B. Zaman, V. vanden Abeele, A. Laenen, 2015. Co-design revisited: exploring problematic co-design dynamics in kids. Proceedings of the SIGCHI Conference on Human Factors in Computing Systems, Paris, France, 27 April - 2 May 2013, (CHI '13), 1-6. [36] R.K. Yin, 2008. Case Study Research: Design and Methods. Applied Social Science Research Methods Series, vol. 5. 
[36] Y. Bergner, O. Chen, 2018, June. Deep making: curricular modules for transferable contentknowledge and scientific literacy in makerspaces and FabLabs. In Proceedings of the 17th ACM Conference on Interaction Design and Children, 551-556.

[37] L. Benton, H. Johnson, 2015. Widening participation in technology design: A review of the involvement of children with special educational needs and disabilities. International Journal of Child-Computer Interaction, 3 (May, 2015), 23-40.

[38] W. Barendregt, P. Börjesson, E. Eriksson, O. Torgersson, T. Bekker, H. M. Skovbjerg, 2018. Modelling the roles of designers and teaching staff when doing participatory design with children in special education." Proceedings of the 15th Participatory Design Conference: Full Papers-Volume 1. ACM, Article No. 9.

[39] L. Benton, 2013. Participatory Design and Autism: Supporting the participation, contribution and collaboration of children with ASD during the technology design process. Ph.D. Dissertation. University of Bath, United Kingdom.

[40] T. Molin-Juustila, M. Kinnula, N. Iivari, L. Kuure, E. Halkola, 2015. Multiple voices in ICT design with children - a nexus analytical enquiry. Behaviour \& Information Technology 34, 11(2015), 1079-1091. 